\title{
Enhanced Anaerobic Treatment of Textile Wastewater by Chemical Additive
}

\author{
Ton That Lang \\ Department of Environmental Engineering, the University of Natural Resources and Environment, Ho Chi Minh City 00848, Vietnam
}

\begin{abstract}
The textile processing plants utilize a wide variety of dyes and other chemicals such as acids, bases, salts, detergents, sizes, oxidants, mercerizing and finishing chemicals. Many of these are not retained in the final product and are discharged in the effluent. Therefore, the objective of this study was to assess the performance of Expanded Granular Sludge Bed (EGSB) reactor to treat synthetic textile wastewater. Several experiments using Direct Red 81 and volatile fatty acids as model substrates were conducted. The problems of decolorization was evaluated at a variety of relevant operational conditions, such as substrate concentration, organic and hydraulic loading rates. The results showed that retention time of EGSB equals $1.6 \mathrm{~h}$ and $80 \mathrm{mg} / \mathrm{L}$ at the hydraulic and dye concentration respectively, and that the color removal efficiency can reach $90 \%$. Additionally, some chemical additions were proposed to improve the decolorization rate and increase the treatment efficiency of the system. For instance, sulfide was added at $200 \mathrm{mg} / \mathrm{L}$ in the influent, which can increase the dye removal efficiency to $95 \%$.
\end{abstract}

Key words: Dye removal, textile wastewater, EGSB.

\section{Introduction}

The textile processing plants utilise a wide variety of dyes and other chemicals such as acids, bases, salts, detergents, wetting agents, sizes, oxidants, mercerizing and finishing chemicals. Many of these are not retained in the final product and are discharged in the effluent. Even little release of effluents may cause abnormal coloration of surface waters, which can capture the attention of both the public and the authorities.

There are several ways in which colorants cause problems in waters. The presence of dyes in natural waters reduces the penetration of sunlight and they may cause toxicity to a variety of organisms. In anaerobic sediments, azo dyes are reduced, generating aromatic amines, some of which are toxic, mutagenicand/or carcinogenic to animal and humans.

The treatment of colored wastewaters therefore is restricted not only to the reduction of ecological parameters (such as chemical oxygen demand (COD), biological oxygen demand (BOD) etc.), but also to the

Corresponding author: Lang Ton That, Ph.D., main research field: wastewater treatment. reduction of dye concentrations in the wastewaters.

In general, dyes containing wastewaters can be treated in two ways: (i) by chemical or physical methods such as chemical coagulation, chemical oxidation, electrochemical treatment, adsorption, ion exchange, membrane etc. [1,2] and (ii) by means of biodegradation methods such as activated sludge, and UASB [3-6]. During conventional aerobic wastewater treatment, azo dyes are not degraded. On the other hand, azo linkages are easily reduced under anaerobic condition with digester sludge, anaerobic granular sludge and sediments [5-7]. The reduction of azo dyes results in the formation of aromatic amines. Most aromatic amines are not mineralized anaerobically. However, the aromatic amines are readily degraded aerobically $[4,5]$.

In an effort to design a cheap and effective bioremediation system for textile industry, an anaerobic system can be used to, at least partially, treat these effluents and provide a number of significant advantages. For many years the benefit and the drawbacks of Expended Granular Sludge Bed (EGSB) reactor have been the subject of discussion. 
With the use of effluent recirculation, liquid upward velocities exceeding $5 \mathrm{~m} / \mathrm{h}$ to $6 \mathrm{~m} / \mathrm{h}$ can be achieved, which is significantly higher than the $0.5 \mathrm{~m} / \mathrm{h}$ to 1.5 $\mathrm{m} / \mathrm{h}$ range generally applied for UASB reactor. This modification can improve wastewater-biomass contact during anaerobic treatment by expending sludge bed and intensifying the hydraulic mixing which enhances the penetration of substrate into biofilm. However, sludge washout may due to excessive expansion of the sludge bed and sludge erosion and deterioration by the high shear forces.

So far, little information is available about the performance of EGSB to treat textile wastewater. Therefore, the objective of this study was to assess the performance of EGSB reactor to treat synthetic textile wastewater. Several experiments using Direct Red 81, and volatile fatty acids as model substrates were conducted. The problems of decolorization was evaluated at a variety of relevant operational conditions, such as substrate concentration, organic and hydraulic loading rates. Additionally, some chemical additions were proposed to improve the decolorization rate and increase the treatment efficiency of the system.

\section{Material and Method}

\subsection{Biomass}

The reactors were inoculated with granular sludge that was obtained from a full scale UASB reactor treating the effluent of a potato processing factory.

\subsection{Reactors}

Experiments were performed using a $0.05 \mathrm{~m}$ diameter glass EGSB reactor (Fig. 1) with total volume $4.3 \mathrm{~L}$ (settler included). Temperature was controlled by

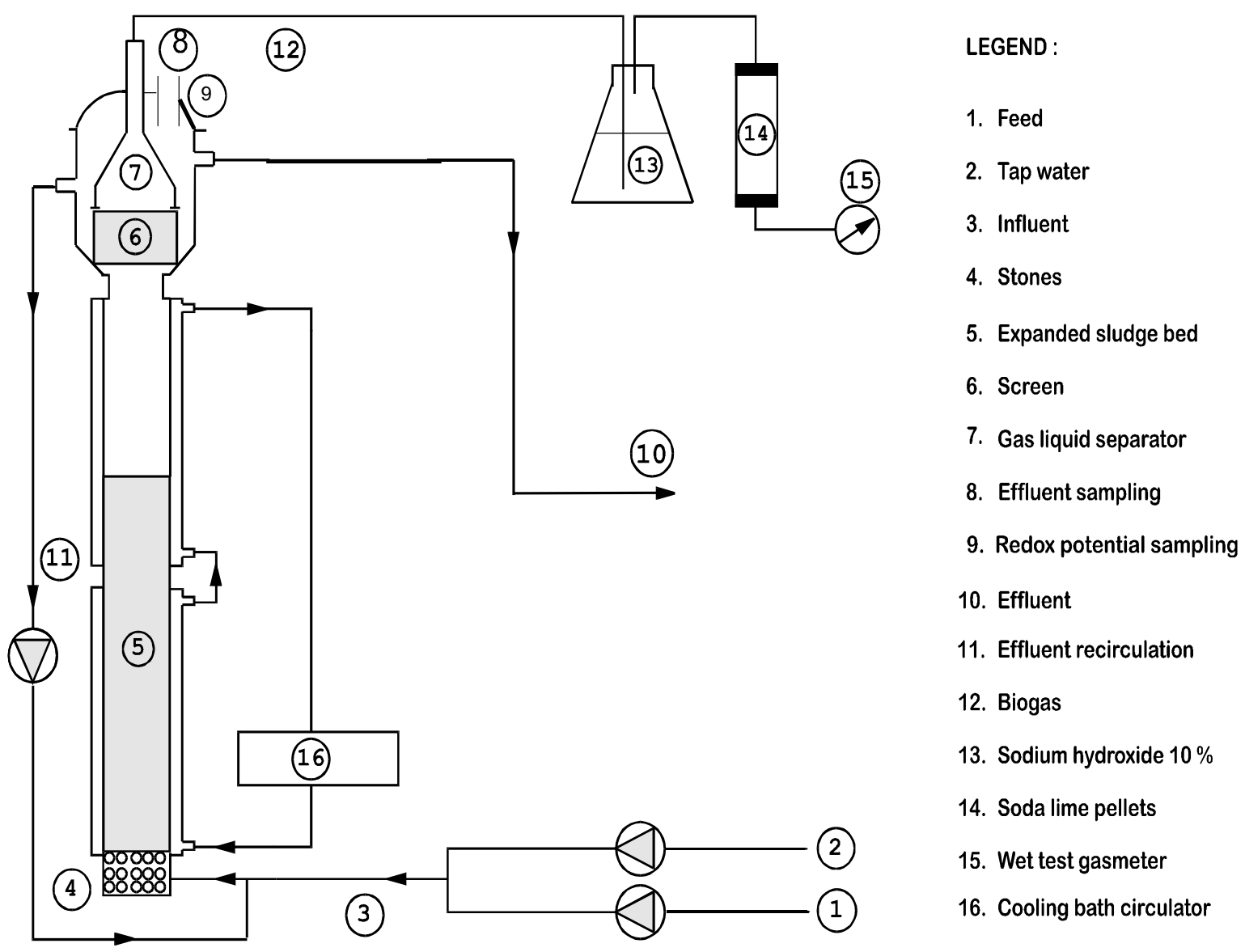

Fig. 1 Schematic diagram of 4.3 L EGSB reactor used in this study. 
thermostat-cooling system which consisted of two different cooling devices (Fryka-Kaltetechnik, Germany and Rheinische Geraetebau GmbH, Switzerland) and a heat-exchanger with the pump (Iwaki magnet pump MD-15R-220N, Tokyo, Japan) connected to the double wall of the reactor. Temperature in the sludge bed was measured with a thermometer (TES 1320 type-K, Taiwan). Methane production was measured by a wet-test gas meter (Meterfaried, Dordrecht, The Netherlands) at $20{ }^{\circ} \mathrm{C}$ after the biogas had been led through a $\mathrm{NaOH}$ solution $(10 \% \mathrm{w} / \mathrm{w})$ and a column of soda lime pillets with indicator (Merck, Darmstadt, Germany). The main flow was provided with a peristatic pump (Watson Marlow 501 U, Falmouth, Cornwakk, UK) pumping tap water of $30-31{ }^{\circ} \mathrm{C}$, to which concentrated feed stock solution was supplied with a separate peristatic pump (Gilson-Minipuls 3, Villiers-Le-Bel, France). Recirculation of the effluent was imposed to the system by a peristatic pump (Wason Marlow $502 \mathrm{~S}$, Falmouth, Corwall, UK), enabling the desired expansion of the sludge bed in the reactor. Tap water, feed stock solution and recirculation flow were combined before entering the reactor.

\subsection{Medium}

The reactor was fed with a concentrated stock solution of $30.0 \mathrm{~g}$ chemical oxygen demand (COD). The substrate consisted of a partly neutralized $(\mathrm{pH}=$ 6.5) mixture of volatile fatty acid (VFA) composed of acetate, propionate and butyrate at the ratio of 1:1.5:1.8, based on COD. The concentrations of basal nutrient in the concentrated stock solution were $\left(\mathrm{g} \cdot \mathrm{L}^{-1}\right)$ : $\mathrm{NH}_{4} \mathrm{Cl}, 7.5, \mathrm{MgSO}_{4} \cdot 7 \mathrm{H}_{2} \mathrm{O}, 1.5, \mathrm{NaH}_{2} \mathrm{PO}_{4} \cdot 2 \mathrm{H}_{2} \mathrm{O}, 27.6$; $\mathrm{K}_{2} \mathrm{HPO}_{4}, 21.2 ; \mathrm{CaCl}_{2} \cdot 2 \mathrm{H}_{2} \mathrm{O}, 0.3$; yeast extract, 0.5. Each litre of stock solution was added containing $\left(\mathrm{mg} \cdot \mathrm{L}^{-1}\right): \mathrm{FeCl}_{2} \cdot 4 \mathrm{H}_{2} \mathrm{O}, 2000 ; \mathrm{H}_{3} \mathrm{BO}_{3}, 50, \mathrm{ZnCl}_{2}, 50$; $\mathrm{CuCl}_{2} \cdot 2 \mathrm{H}_{2} \mathrm{O}, \quad 30 ; \quad \mathrm{MnCl}_{2} \cdot 4 \mathrm{H}_{2} \mathrm{O}, \quad 500$; $\left(\mathrm{NH}_{4}\right)_{6} \mathrm{Mo}_{7} \mathrm{O}_{24} \cdot 4 \mathrm{H}_{2} \mathrm{O}, \quad 50 ; \quad \mathrm{AlCl}_{3} \cdot 6 \mathrm{H}_{2} \mathrm{O}, \quad 90$; $\mathrm{NiCl}_{2} \cdot 6 \mathrm{H}_{2} \mathrm{O}, 92 ; \mathrm{Na}_{2} \mathrm{SeO}_{3} \cdot 5 \mathrm{H}_{2} \mathrm{O}, 164$; EDTA, 1000 ; resazurin, $200 ; \mathrm{HCl} 36 \%, 1 \mathrm{~mL} \cdot \mathrm{L}^{-1}$. All chemicals were of analytical grade and purchased from Merck (Darmstadt, Germany).

\subsection{Start-up of the Reactor}

Feeding of the reactor was started immediately after inoculation with the mesophilic granular sludge, at an organic loading rate (OLR) of 15-20 g COD $\cdot \mathrm{L}^{-1} \cdot \mathrm{d}^{-1}$ and a hydraulic retention time (HRT) of $1.2 \mathrm{~h}$. From the start of the experiment the temperature of the reactor was set at $30{ }^{\circ} \mathrm{C}$. During the continuous operation of the reactor, the samples of influent and effluent were taken three times per week in duplicate.

\subsection{Batch Experiment}

\subsubsection{Anaerobic Sulfate Reduction Assay}

The batch anaerobic assays were conducted in 120 $\mathrm{mL}$ glass serum flasks. The basal medium used in the bioassay was $\left(\mathrm{g} \cdot \mathrm{L}^{-1}\right): \mathrm{NH}_{4} \mathrm{Cl}, 2.8, \mathrm{CaCl}_{2}, 0.047$, $\mathrm{K}_{2} \mathrm{HPO}_{4}, \quad 2.5, \quad \mathrm{MgCl}_{2} \cdot 7 \mathrm{H}_{2} \mathrm{O}, \quad 5.0$ with $50 \mathrm{~mL}$ micronutrient. Predigested granular sludge $(1.5 \mathrm{~g}$ $\left.\mathrm{VSS} \cdot \mathrm{L}^{-1}\right)$ was transferred to serum flasks containing 5 $\mathrm{ml}$ of the basal medium, $45 \mathrm{~mL} \mathrm{NaHCO}_{3}$ solution (5 $\left.\mathrm{g} \cdot \mathrm{L}^{-1}\right)$ and $1 \mathrm{~mL}$ of VFA ( $85 \mathrm{~g} \mathrm{COD} \cdot \mathrm{L}^{-1}, \mathrm{C} 2: \mathrm{C} 3: \mathrm{C} 4=$ 1:1:1 based on COD) from neutralized stock to yield a final concentration of $1.5 \mathrm{~g}$ of $\mathrm{COD} \cdot \mathrm{L}^{-1}$. The serum flasks were sealed with $12 \mathrm{~mm}$ thick butyl rubber stoppers (Rubber B.V., Hilversum, The Netherlands) and flushed with $70 \% \mathrm{~N}_{2}-30 \% \mathrm{CO}_{2}$ gas for 5 minutes and incubated with shaking $(50 \mathrm{rpm})$ overnight in a temperature control room at $30{ }^{\circ} \mathrm{C}$ for two days to allow for biological consumption of residual $\mathrm{O}_{2}$.

After two days of incubation, the serum flasks were fed with $1 \mathrm{~mL}$ of VFA and $1 \mathrm{~mL}$ of $\mathrm{Na}_{2} \mathrm{SO}_{4}$ to ensure the concentration of sulfate in the serum bottles about $2 \mathrm{~g} \cdot \mathrm{L}^{-1}$ and flushed with $70 \% \mathrm{~N}_{2}-30 \% \mathrm{CO}_{2}$ gas for 5 minutes. The sulfide concentration in the solution of each serum flask was monitored periodically during the assay. Sludge blanks, to correct for background sulfide production from the sludge, were based on assays where no sulfate compound were provided. Sulfide concentration was calculated by substracting 
background sulfide production in the control from that in the test vials. All data are the average of triplicate run experiments.

\subsubsection{Anaerobic Decolorisation Assay}

The basal medium, sludge, and procedure to carry out the assay are similar to those which were mentioned above. After two days incubation the serum flasks were fed with $1 \mathrm{~mL}$ of VFA, $1 \mathrm{~mL}$ of Direct Red 81 (DR81) concentration $200 \mathrm{mg} \cdot \mathrm{L}^{-1}, 1$ $\mathrm{mL}$ of adding compound $\left(\mathrm{SO}_{4}, \mathrm{~S}^{2-}\right.$, Anthraquinone 2-sulfonic acid) provided and flushed with $70 \% \mathrm{~N}_{2}-30 \%$ $\mathrm{CO}_{2}$ gas for 5 minutes. All data are the average of triplicate run experiments. The absorbance of DR81 was monitored periodically (0-10 hour) during the assay. The absorbance was transferred to the concentration by the calibration curve. The initial reduction rate was calculated based on linear part of the graph, omitting the lag phase.

\section{Analyses}

\subsection{Sulfide}

Sulfide was measured colorimetrically, using a method adapted from Ref. [8].

\subsection{Sulphate}

Sulphate were determined according to standard methods [1].

\subsection{Wave Length}

Wave length at maximum absorbance was defined by scanning the Direct Red 81 sample with spectrophotometer at wave length $509 \mathrm{~nm}$.

\subsection{Absorbance}

The absorbance at $509 \mathrm{~nm}$ was measured with a $\begin{array}{lll}\text { spectronic } & 60 & \text { spectrophotometer (Milton }\end{array}$ Roy/Analytical Products Division, Ostende, Belgium) and a model 100-QS (Hellma Benelux, The Hague, The Netherlands) $1-\mathrm{cm}$ quartz cuvette. All samples were diluted to less than 0.9 absorbance units in $0.2 \mathrm{M}$ phosphate buffer ( $\mathrm{pH} 7.0)$.

\section{Results}

\subsection{Anaerobic Sulfate Reduction Assay}

The result of anaerobic sulfate reduction assay was showed in Fig. 2. The lag phase was about 1.2 days, ang then the rate increased to $60 \mathrm{~g} /$ hour.

Different concentration of sulfate was used to assess the effect of sulfate on the decolorization rate of DR81. The sulfate concentration in the bottles were 0 (blank), 0.02, 0.20, 0.50, 1.00, $2.00 \mathrm{~g} \cdot \mathrm{L}^{-1}$ and 0.0 , $0.001,0.005,0.010,0.020,0.04 \mathrm{~g} \cdot \mathrm{L}^{-1}$. The results showed that there is no significant effect of sulfate concentration on the decolorization rate of DR81, not only at low concentration (Fig. 4) but also at high concentration of sulfate (Fig. 3).

\subsection{Anaerobic Decolorisation Assay with the Presence of Anthroquinone-2-sulfonic acid (AQS)}

There is no clearly effect of AQS on the decolorization rate of DR81 (Fig. 5).

\subsection{Anaerobic Decolorisation Assay with the Presence of Sulfide}

Different concentration of sulfide was used to assess the effect of sulfide on the decolorization rate of DR81. The sulfide concentration in the bottles were 0 (blank), $0.01,0.02,0.05,0.20 \mathrm{~g} \cdot \mathrm{L}^{-1}$. To evaluate the importance of biological action and chemical reduction on the decolorization rate of DR81, the sterilized sludge and the samples without sludge were introduced. The results showed that there is a significant effect of sulfide on the decolorization rate of DR81 (Fig. 5). At low concentration of Sulfide

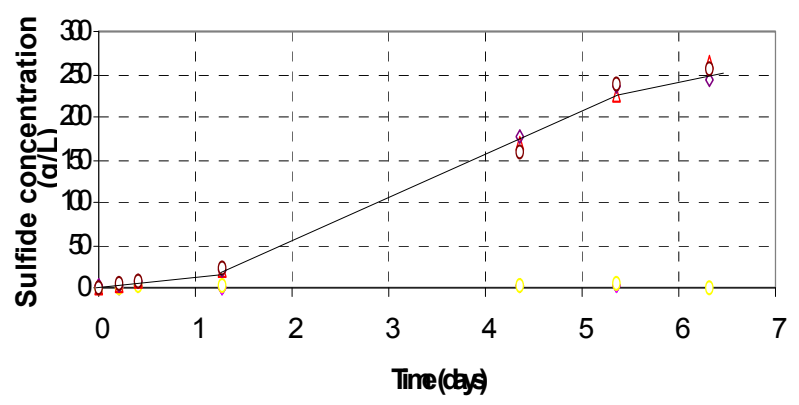

Fig. 2 Sulfide generation vs. time. 


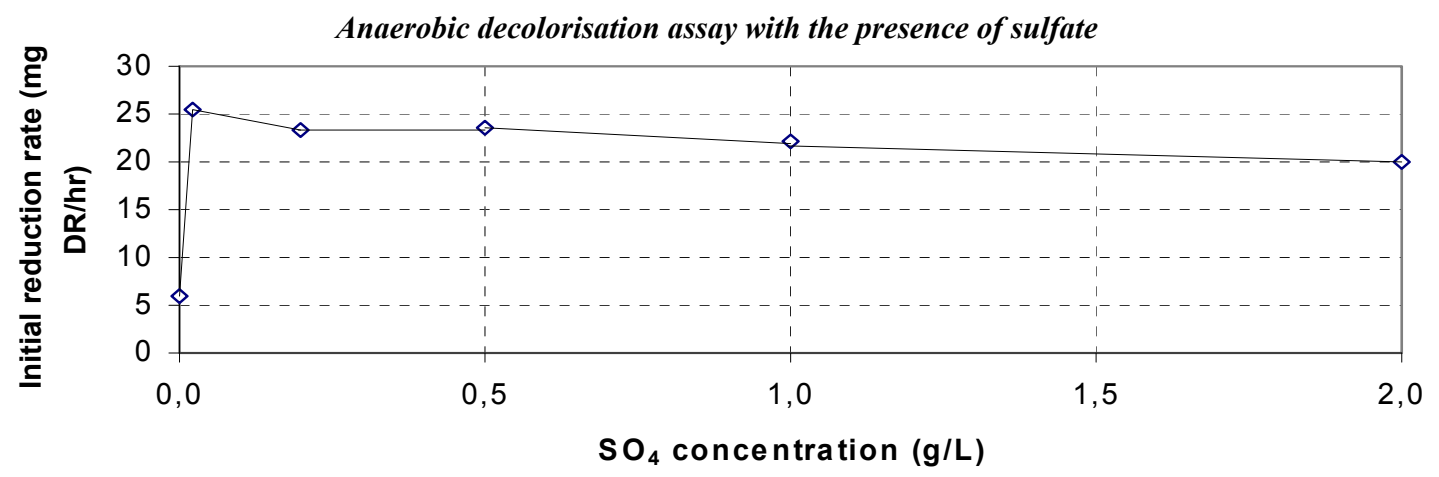

Fig. 3 The initial reduction rate of Direct Red 81 at different concentration of sulfate.

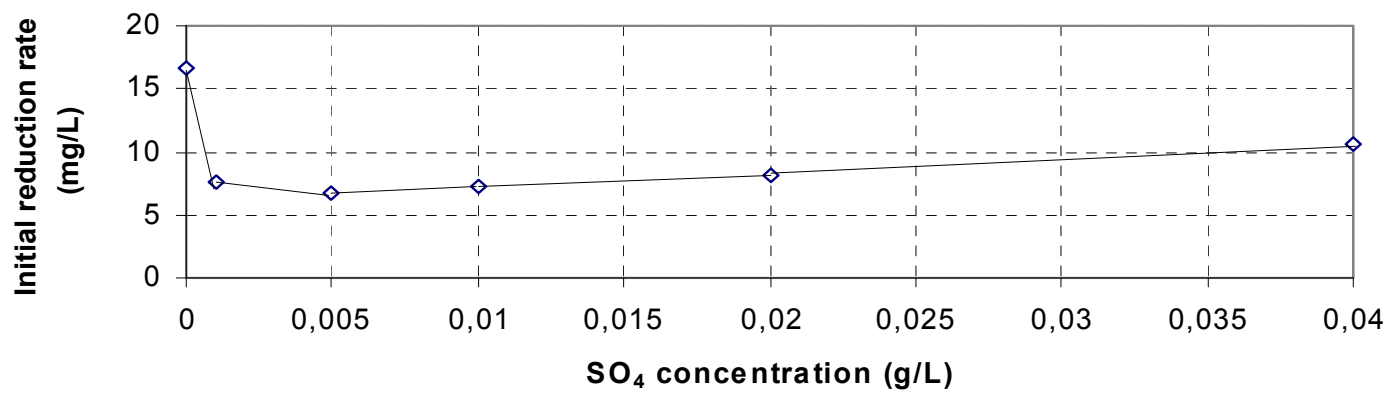

Fig. 4 The initial reduction rate of Direct Red 81 at low concentration of sulfate.

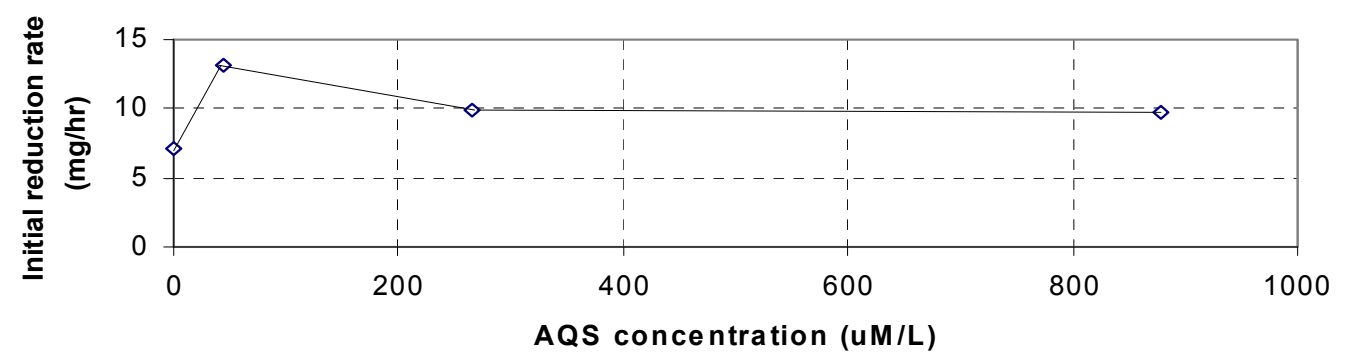

Fig. 5 The initial reduction rate of Direct Red 81 at different concentration of AQS.

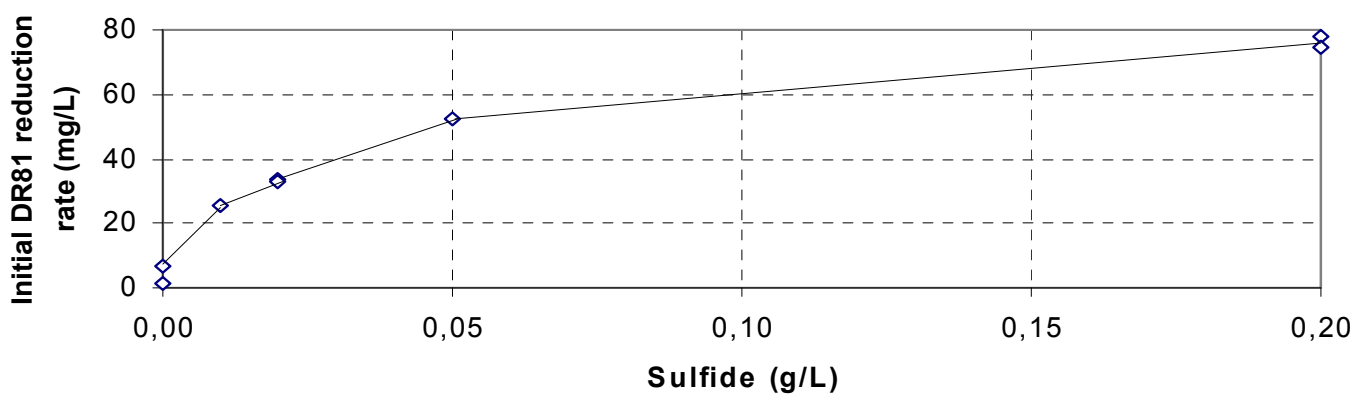

Fig. 6 The initial reduction rate of Direct Red 81 at different concentration of AQS.

$\left(0.20 \mathrm{~g} \cdot \mathrm{L}^{-1}\right)$, the decolorization rate increased 11 times: from $7.1 \mathrm{mg} \cdot \mathrm{L}^{-1}$ to $78.1 \mathrm{mg} \cdot \mathrm{L}^{-1}$.

\subsection{Reactor Performance}

In this experiment two periods can be distinguished, namely days 0-28 (supply with dye, HRT $=1.2 \mathrm{hr}$ ) and 29 to 72 (supply with dye, HRT = $1.6 \mathrm{hr}$ ). The summary the operational condition of EGSB reactor from the beginning to the end of experiment was presented in the Table 1 and Fig. 7. 

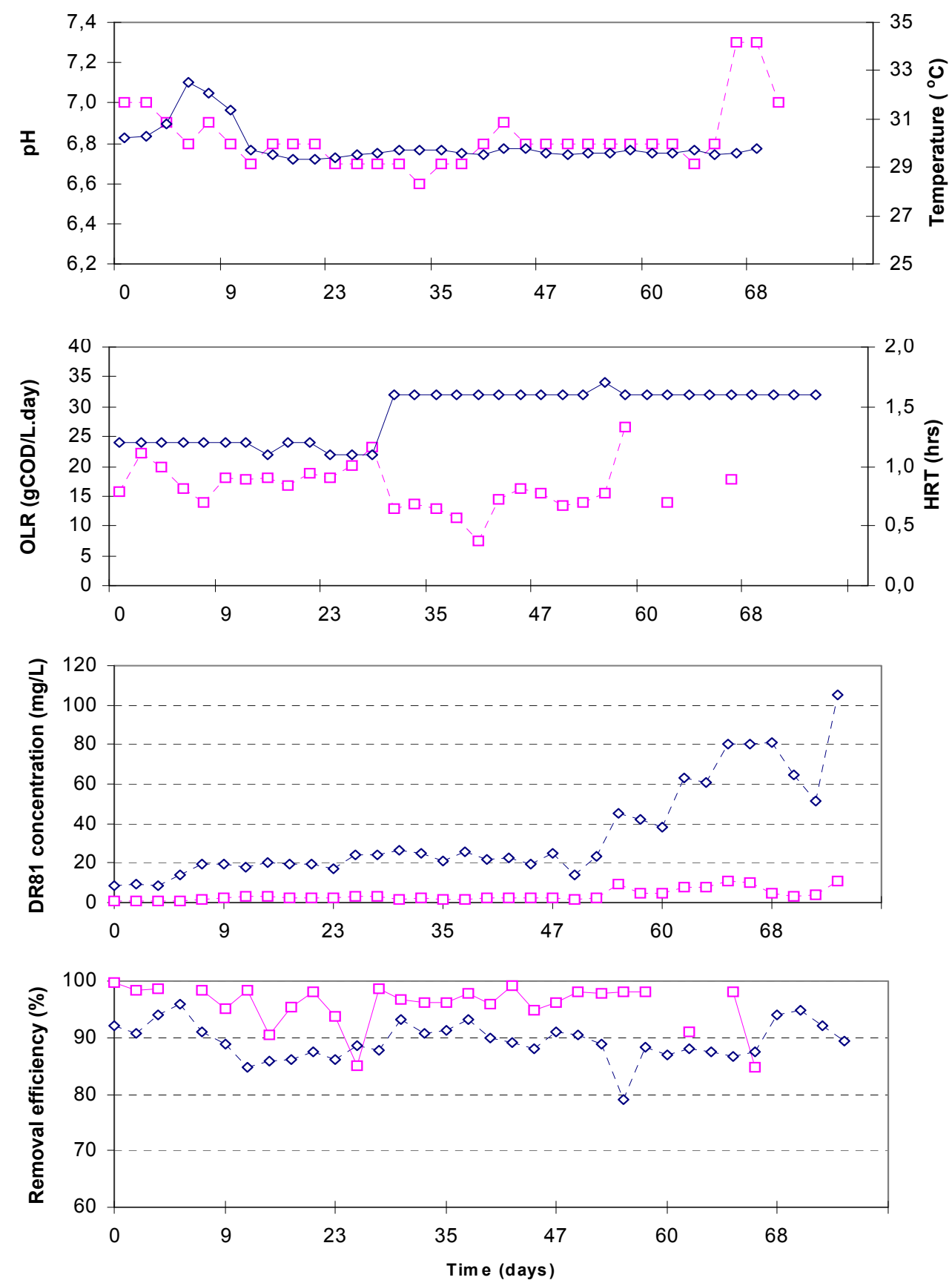

Fig. 7 The performance of EGSB to treat DR81.

Table 1 Operational condition of EGSB reactor.

\begin{tabular}{lllllll}
\hline Period & $\mathrm{T}$ & Dye conc. & HRT & OLR & \multicolumn{2}{c}{ Efficiency } \\
\hline$($ day $)$ & $\left({ }^{\circ} \mathrm{C}\right)$ & $(\mathrm{mg} / \mathrm{L})$ & $($ hour $)$ & $\left(\mathrm{g} \mathrm{COD} \cdot \mathrm{L}^{-1} \cdot \mathrm{day}^{-1}\right)$ & $\mathrm{COD}$ & $\mathrm{CH}{ }^{-} \mathrm{COD}$ \\
\hline $0-6$ & 30 & 10 & 1.2 & $15.0-20.0$ & $>95$ & 75 \\
$7-28$ & 30 & $20-25$ & 1.2 & $15.0-20.0$ & $>95$ & $70-75$ \\
$29-52$ & 30 & $20-25$ & 1.6 & $13.0-15.0$ & $>95$ & $75-80$ \\
$53-63$ & 30 & $40-60$ & 1.6 & $14.0-15.0$ & $>95$ & $70-80$ \\
$64-72$ & 30 & $60-100$ & 1.6 & $15.0-20.0$ & $>95$ & $60-70(*)$ \\
\hline
\end{tabular}

(*) Started adding $\mathrm{S}^{2-}$. 


\section{Conclusion}

- Sulfate and anthraquinone-2-sulfonic acid have no significant effect on the decolorization rate of DR81;

- Sulfide has positive effect on decolorization rate of DR81;

- At HRT $=1.6$ hour and the DR81 influence concentration $=80 \mathrm{mg} / \mathrm{L}$, the removal efficiency can reach at $90 \%$;

- If sulfide was added to $200 \mathrm{mg} / \mathrm{L}$ in the influent, It can improve the dye removal efficiency, up to $95 \%$.

\section{Recommendation}

The combination of electron donor and redox mediator for continuous reactor, the biodegradation path way of DR81, and the performance of EGSB reactor with real textile wastewaters needs further researches.

\section{References}

[1] Lopez Grimau, V., Riera-Torres, M., and GutierrezBouzan, C. 2013. "Removal of Aromatic Amines and
Decolourisation of Azo Dye Baths by Electrochemical Treatment." Coloration Technology 129 (4): 267-273.

[2] Verma, A., Nath, D., Bhunia, P., and Dash, R. 2016. "Application of Ultrasonication and Hybrid Bioreactor for Treatment of Synthetic Textile Wastewater." Journal of Hazardous, Toxic, and Radioactive Waste 213-21.

[3] Mahdi, A., Azni, I., and Aofah, A. 2007. "Combine Anaerobic-aerobic System for Treatment of Textile Wastewater." Journal of Engineering Science and Technology 2 (1): 55-69.

[4] Oh, Y., Kim, Y., and Ahn, Y. 2004. "Color Removal of Real Textile Wastewater By Sequential Anaerobic and Aerobic Reactors.” Biotechnology Bioproc E 9: 419.

[5] Popli, S. and Patel, U. 2015. "Destruction of Azo Dyes by Anaerobic-aerobic Sequential Biological Treatment: A Review." International Journal of Environmental Science and Technology 12 (1) 405-420.

[6] Venkatesh, B. S., Raghupathy, S., and Rajasimman, M. 2016. "Anaerobic Treatment of Textile Dye Wastewater Using Mixed Culture in Batch Reactor." Journal of Advanced Chemical Sciences 2 (2): 233-236.

[7] Sen, S., and Demirer, G. N. 2003. "Anaerobic Treatment of Real Textile Wastewater with A Fluidized Bed Reactor." Water Resource 37 (8) 1868-1878.

[8] APHA, WPCF, and AWWA. 1999. Standard Methods for the Examination of Water and Wastewater. Washington DC.: American Publish Health Association. 